\title{
QALÂNDIA: MURO FECHADO
}

Maitê Pereira Lamesa ${ }^{1}$

\section{Introdução e Abordagem}

0 presente trabalho se apresenta como um relato de campo esse refere ao mês de março de 2013, quando residi em Ramallah - Cisjordânia e diariamente cruzava um dos mais conhecidos postos de controle israelense: o Qalândia.

0 relato, contudo, não se limita a esse período e as experiências pessoas nele contidas, fiz constantemente uso de contextos históricos e vali-me, sobretudo, de normas de direito internacional para fundamentar tais experiências no local. Por se tratar aqui de uma vivência, com uma boa carga de subjetividade, há igualmente momentos em que me reporto a outros períodos, que dão um caráter mais lógico a pensamentos e ponderações sobre essa experiência.

Assumem uma importância particular os relatos de pessoas por revelar o lado prático de questões que, na maioria das vezes, são apenas abordadas sob o ponto de vista teórico, e, em que pese o texto traga alguma carga emocional pessoal, a contextualização do tema almeja justamente conectar cada memória com a realidade e com a discussão atual sobre o tema.

Espera-se contribuir para o debate sobre a questão palestina, especificamente no ponto da construção do Muro israelense ao redor dos territórios ocupados: Cisjordânia e Jerusalém Oriental, e contribuir ainda de uma forma mais sensorial o que representa cruzar esse ou qualquer outro Checkpoint na região.

\footnotetext{
1 Maitê Pereira Lamesa é advogada, graduada pela Universidade Estadual de Londrina. Voluntária da FFIPP-Brasil, residiu em Jerusalém Oriental e Ramallah, onde estagiou na Civic Coalition for Palestinian Rights in Jerusalem e Mattin Group, respectivamente.
} 


\section{Muros e checkpoints: a travessia do Qalândia}

Todo o indivíduo legalmente no território de um Estado tem o direito de circular livremente e de aí escolher livremente a sua residência. [Art. 12(1) do Pacto Internacional de Direitos Civis e Políticos de $1966 .{ }^{2}$

A definição de checkpoint ou posto militar, na Cisjordânia, é uma tarefa árdua. Enquanto ponto de passagem, ele é muito mais que um portão, e isso ficou claro desde o primeiro dia em que passei pelo Qalândia. Para os palestinos, cada um dos 26 checkpoints é um ponto de controle e uma barreira à sua liberdade de locomoção elementos que se unem em um sentimento de profunda humilhação -, revestido de catracas, um concreto gélido, soldados espalhados, raio-x, travas, filas e trânsito.

Para os israelenses, significam proteção contra atentados e outros atos de violência e, resumidamente, é isso que se vê escrito nas enormes placas em vermelho com uma mensagem especialmente a eles dirigida: atenção, cuidado, perigo para suas vidas. Já para o direito internacional, crimes de guerra cometidos por Israel, pela afronta à IV Convenção de Genebra, conforme a Resolução 41/63 da Assembleia Geral da ONU. Passo por Qalândia com destino a Beit Hanina e só consigo pensar na frágil estabilidade do local, e na calmaria como uma sensação enganosa.

Essa realidade foi concretizada por Israel no início do Século XXI, o primeiro passo: a aprovação pelo então primeiro ministro israelense Ehud Barak de um plano para construir um muro na região norte e central da Cisjordânia, em novembro de 2000. 0 fracasso de Oslo, a Segunda Intifada (Al-Aqsa Intifada) e a Operação Israelense Defensive Shield - a maior operação desde a guerra de 1967 - resultaram na aprovação pelo gabinete israelense, em junho de 2002, do muro com rota a ser definida pelo primeiro ministro e pelo ministro de defesa.

Desde então, o muro com extensão final de 708 quilómetros, com 61,8\% concluso até abril de 2012, vem limitando o trânsito de palestinos provenientes da Cisjordânia, confiscando e anexando terras palestinas, transferindo forçadamente a população local, e fragmentando por completo a Cisjordânia.

2 ICCPR (1966). "Everyone lawfully in the State shall, within that territory, have the right to liberty of movement and freedom to choose his residence.". In CARECCIA, Grazia; MONAGHAN, Lisa. The Annexation Wall and its Associated Regime. Ramallah: Al-Haq, 2012, p. 42. Ainda, para acessar a integra do Pacto Internacional pelos Direitos Civis e Políticos de 1966: < http://www.gddc.pt/direitos-humanos/textosinternacionais-dh/tidhuniversais/cidh-dudh-direitos-civis.html>. Acesso em: 14/09/2914. 
Assim, nesse um mês de travessia diária do Qalândia, reparo que ele cumpre bem suas funções de segregação e anexação, ocultadas sob o pano transparente da defesa e da proteção. O Muro da Anexação, como denominado por John Dugard, ex-relator especial da ONU sobre a Palestina, é acima de tudo uma agressão em sua imagem pálida, a barreira concreta, e no cinismo dos checkpoints: "os procedimentos são para sua própria segurança". A razão pela qual a construção do muro de forma não coincidente com a linha do armistício de 1949 também está fundada para o governo israelense na necessidade de segurança. Nas minhas idas e vindas através do Qalândia, vejo antes um bloqueio quotidiano, constante, implacável, uma humilhação trivial que só é possível pela segregação de dois povos nos polos de poder ocupante e de ocupado.

Num emaranhado de carros parados no trânsito artificial, nas paradas aleatórias dos taxis que lançam passageiros à rua, ainda a dezenas ou centenas de metros da entrada, o ônibus $\mathrm{n}$ - 18 , único transporte coletivo que conecta Jerusalém Oriental a Ramallah e que raramente permanece cheio quando soldados se aproximam para subir e checar os passageiros. A rotina é repetitiva e ainda assim consegue ser imprevisível, quase me sentia uma palestina, mas minha angústia reduzia-se ao transtorno da espera.

Ao longo da espera, a análise dos detalhes inconsciente me toma num átimo, as bitucas nos cantos, os chicletes colados no chão, as placas distintas dos carros e ônibus, as pessoas que se entreolham em tom de indagação, mesmo já sabendo todas as respostas, as discussões com os soldados e entre eles mesmos. A ansiedade é o que preenche os espaços cinzas. A iminência é o que os define. Os confrontos: soldados e seus fuzis, alguns palestinos e pedras. Muito gás lacrimogênio, bombas de efeito moral, balas de borracha e outras vezes, balas reais.

Na condição de estrangeira, minha passagem dificilmente seria recusada, embora dia após dia o medo de finalmente me barrarem aumentasse. Muitas vezes era aconselhada nos ônibus a não descer, pois eventualmente os soldados permitiriam minha passagem sem que fosse necessário passar pelas filas e catracas. Recusava, descia, ia às filas onde ouvia conversas e discussões, e via ansiedade e uma resignação mesclada aos olhares de inconformismo. Chegava quase sempre um pouco atrasada para o trabalho, embora ele ficasse a pouco mais de um quilômetro do Qalândia.

A checagem é compartilhada por soldados, vestindo o tradicional uniforme verde-oliva e pela companhia de segurança privada G4S (Group4Security), sendo que israelenses e palestinos são empregados da multinacional britânica, carregando 
indistintamente os pesados fuzis nos ombros, atentos às placas de carros e aos documentos que as pessoas carregam consigo.

Os feriados e finais de semana judaicos eram mais complicados, com o portão exclusivo para ônibus fechado e um funcionamento parcial das cabines de checagem, havia mais trânsito e mais fila, mais do mesmo ritual. Como o funcionamento dos checkpoints segue o calendário judaico, semanalmente havia dias em que a rotina de se locomover para o trabalho se agravava, exceto para os palestinos que trabalham em empresas israelenses.

Março, 2013. Obama visita Israel pela primeira vez desde o início de seu segundo mandato. 0 discurso assume um lado claro naquela região em que as narrativas são cruciais, enquanto o peito palestino se aperta, quase vira pedra. 0 suporte que Obama oferece no discurso em solo palestino, ao lado de Abbas, palavras ao vento, vazias, nada de que os palestinos realmente precisam. O Qalândia se cobre de um especial tumulto, dias de confrontos, dificuldades ao atravessá-lo, transporte escasso e uma tensão que amedrontava.

\section{0 muro visto de cima: o parecer consultivo da Corte Internacional de Justiça (2004)}

Em 10 de dezembro de 2003 a Assembleia Geral da ONU requisitou à Corte Internacional de Justiça um parecer consultivo a partir da Resolução 10/14 acerca das consequências legais da construção do muro construído por Israel na Cisjordânia e em Jerusalém Oriental. 0 parecer da Corte considerou o muro como ilegal e estruturou-se em três pontos: (1) a jurisdição da Corte; (2) a legalidade da construção do muro nos territórios ocupados e, finalmente, (3) as consequências legais das violações identificadas.

0 documento refuta explicitamente o argumento de Israel de que a construção do muro é condizente com o princípio da autodefesa, ínsito no artigo 51 da Carta da $\mathrm{ONU}^{3}$, e

\footnotetext{
3 "Art. 51. Nada na presente Carta prejudicará o direito inerente de legítima defesa individual ou colectiva, no caso de ocorrer um ataque armado contra um membro das Nações Unidas, até que o Conselho de Segurança tenha tomado as medidas necessárias para a manutenção da paz e da segurança internacionais. As medidas tomadas pelos membros no exercício desse direito de legítima defesa serão comunicadas imediatamente ao Conselho de Segurança e não deverão, de modo algum, atingir a autoridade e a responsabilidade que a presente Carta atribui ao Conselho para levar a efeito, em qualquer momento, a acção que julgar necessária à manutenção ou ao restabelecimento da paz e da segurança internacionais."
} 
nas Resoluções 1368 e 1373, ambas aprovadas no Conselho de Segurança em 2001. Os dispositivos garantem o direito à autodefesa em casos de ataques armados de um Estado a outro, o que não se aplica a Israel, posto que não há ameaça externa, a suposta ameaça origina-se dentro do território que o próprio país controla.

Condena, ainda, a construção do muro em decorrência das normas imperativas, de efeito erga omnes, que Israel viola e, nesse sentido, lança um pedido a todos os demais Estados signatários:

Given the character and the importance of the rights and obligations involved, the Court is of the view that all States are under na obligation not to recognize the illegal situation resulting from the construction of the wall in the Occupied Palestinian Territory, including in and around East Jerusalem. ${ }^{4}$

À parte essa condenação direta da construção do muro por Israel, poucas medidas são tomadas no bojo da comunidade internacional, receosa de endereçar ao país represálias e sanções previstas pelo direito internacional. Interesses comerciais tornam, de modo geral, esse direito de todos os povos relativo e com poder de coerção limitado, o que se mistura à sensação de desolação ante a contemplação de muro e de checkpoints que, embora ilegais, seguem sendo a realidade no local.

\section{Segurança de uns ou punição coletiva de outros?}

Não se pode esperar que todo mundo fique feliz com a barreira. ${ }^{5}$

O muro e os checkpoints criaram lados e consolidaram uma divisão de duas sociedades que já existia antes. Contudo, ainda assim, eles são uma imposição e não uma necessidade, uma estrutura de dominação e, como tal, servem a interesses exclusivos de

In Carta das Nações Unidas. Disponível em: < http://www.gddc.pt/direitos-humanos/textosinternacionais-dh/tidhuniversais/onu-carta.html>. Acesso em: 03/09/2014.

4 ICJ (International Court of Justice. Advisory Opinion on Legal Consequences of the Construction of a Wall in the Occupied Palestinian Territory. Disponível em: <http://www.icjcij.org/docket/index.php?p1=3\&p2=4\&case=131\&p3=4>. Acesso em 12/07/2014.

5 BACKMANN, René. Um Muro na Palestina. Tradução de Clóvis Marques. Rio de Janeiro: 2012, p. 125. A frase é do antigo presidente do Conselho de Segurança Nacional israelense, Uzi Dayan. Sobre as reais intenções de Israel ao construir a barreira na Cisjordânia “(...) a estratégia inconfessada, mas perfeitamente verificável no terreno concreto, dos governos de Sharon a Olmert, a estratégia desenvolvida por Dany Tirza: assegurar a expansão e garantir a segurança das colônias israelenses destinadas a serem anexadas, qualquer que seja o preço para as localidades palestinas vizinhas" (p. 125). 
Israel e punem indistintamente a sociedade palestina. Controle diário é um peso muito grande a palestinos que vão ao trabalho, aos hospitais, visitar familiares que vivem em território israelense, ou mesmo na Cisjordânia que acabou por ficar do lado de dentro do muro ou que se tornaram enclaves, como Qalqiliya.

Assim, o muro é um ônus inteiramente transferido à população palestina exclusivamente, e para Israel não há um problema nisso, mesmo se o texto da IV Convenção de Genebra (1949), em seu artigo 33 assim disponha:

Nenhuma pessoa protegida pode ser castigada por uma infração que não tenha cometido pessoalmente. As penas coletivas, assim como todas as medidas de intimação ou de terrorismo, são proibidas. A pilhagem é proibida. As medidas de represália contra as pessoas protegidas e seus bens são proibidas. ${ }^{6}$

A proteção em Israel é seletiva, e não vale para as pessoas sob sua tutela, as "pessoas protegidas", conforme o artigo 4ํ da referida Convenção. E mais, ela é preventiva, ou seja, a punição é antecipada e em resposta a um possível (futuro) crime que venha a ser cometido em Israel por um palestino. Já a proteção de um possível (futuro) crime que venha a ser cometido por um israelense em território palestino não é garantia, vez que para eles a passagem é livre. Ante um crime "provável", o muro é a resposta que coloca todos os palestinos da Cisjordânia como terroristas em potencial.

A punição, além da faceta das liberdades fundamentais de cada indivíduo, bem como violações ao Direito Humanitário Internacional, também pesa economicamente para os palestinos:

\begin{abstract}
Nossos limões, nossas azeitonas, nossas goiabas eram exportadas até para a Arábia Saudita e os emirados do Golfo. Agora, não podemos mais vendê-los nem mesmo em Nablus ou Jenin. De pé com um cesto na mão no meio de uma plantação de tomates já agora amputada pela pista de patrulha do muro. Assad Atalla lançava ao redor um olhar desesperado. Esse lote espremido entre a rodovia e o muro era tudo que lhe restava das terras herdadas da família. 0 resto estava debaixo do cimento ou inacessível, do outro lado. "Mas o pior" confessara o agricultor, na casa dos 50 anos, visivelmente furioso com a impotência a que fora reduzido, "é que eles arrancaram diante dos nossos olhos quase 8 mil oliveiras, carregando-as em caminhões. E quando perguntamos aos soldados o que fariam com elas, eles responderam que não podiam dizer nada, pois era uma questão de segurança. ${ }^{7}$
\end{abstract}

\footnotetext{
${ }^{6}$ ICRC. IV Convenção de Genebra (1949). Disponível em: < http://www.gddc.pt/direitos-humanos/textosinternacionais-dh/tidhuniversais/dih-conv-IV-12-08-1949.html >. Acesso em: 14/09/2014.

${ }^{7}$ BACKMANN, René. Um Muro na Palestina. Tradução de Clóvis Marques. Rio de Janeiro: 2012, p. 127.
} 
Do outro lado do muro, pouco de sabe sobre o preço que se paga na Cisjordânia para que Israel seja um lugar seguro e, na medida em que Israel é construído para israelenses, de preferência judeus, não se vai querer saber.

\section{Luz verde: a ilusão da última catraca}

Luz verde acesa, avanço pela última catraca e deixo o Qalândia. Por volta das 22 horas é já impossível encontrar locomoção direta entre Ramallah e Jerusalém, avanço num carro, lembrando das luzes vermelha e verde que travam e liberam as catracas.

$\mathrm{Na}$ mente, aqueles intervalos de tempos curtíssimos e específicos em que se respirava nas filas do Qalândia, ainda com as mãos inconscientemente cerradas. Israelenses protegidos dos possíveis ataques terroristas, a salvo nos cafés, restaurantes, nos cantos em que se ouvia um jazz em Jerusalém Ocidental, ou nas festas e na praia de Tel Aviv, muitos não conhecem o Qalândia ou qualquer outro checkpoint, por vezes pela existência da luz vermelha do estigma, da categorização de 'território seguro' e 'território inimigo' e, portanto, perigoso. Por essa ótica, o muro é nada mais do que delimitar onde é seguro e onde não o é, estabelecendo, por consequência, espaços apartados destinados a uma população específica.

Ao se cruzar um checkpoint definitivamente está implícita essa questão de representar um perigo em potencial a Israel, lá todos o são e sobre esse pressuposto, o Qalândia subsiste, escorando-se em medidas muito mais agressivas que defensivas.

Assim, a própria existência do Qalândia em solo palestino, assim como todos os outros checkpoints, é uma agressão, e a paz do lado ocupante vale vezes mais que a proteção do solo palestino ocupado, paz e liberdade tornaram-se uma ilusão. Cruzar a última catraca dá a falsa sensação de libertação. Uma libertação momentânea e ilusória: no próximo amanhecer, o Qalândia novamente se apresenta para todos os palestinos com suas tantas luzes vermelhas. Palestino que, a princípio, precisam ir até Jerusalém, e não cruzar, atravessar, transpor algo. Apresenta-se como a barreira artificial mais concreta que se pode vivenciar, e essa barreira é também o obstáculo da própria humanidade ao aplicar seus valores máximos e compromissos imperativos, os direitos humanos. 


\section{Edward Said e Mahmoud Darwish: após o último céu}

$$
\begin{array}{r}
\text { The Earth is closing on us } \\
\text { pushing us through the last passage } \\
\text { and we tear off our limbs to pass through. } \\
\text { The Earth is squeezing us. } \\
\text { I wish we were its wheat } \\
\text { so we could die and live again. } \\
\text { I wish the Earth was our mother } \\
\text { so she'd be kind to us. }
\end{array}
$$

(...)

Where should we go after the last frontiers ? Where should the birds fly after the last sky?

Em 25 de setembro do presente ano contam-se 11 anos da morte de umas das vozes que mais se ergueu em favor dos Palestinos: Edward Said. 0 escritor nunca se afastava das palavras do poeta ícone da resistência palestina - Mahmoud Darwish -, e parte de um dos versos do poema The Earth is Closing on Us tornou-se o título de um de seus livros: "After the Last Sky".

"Calamidade" e "renascimento" são expressões empregadas por Said ao interpretar o poema de Darwish, pois exprimem com clareza a situação dos palestinos. 0 Muro da Separação não diz outra coisa, a ideia é de um cerco constante.

Há um elemento esperançoso nas palavras de Said: “(...) transpor o último céu e a última passagem sugere que, embora pareçam ser os últimos, ainda há outra via, há outro céu, há outro terreno do outro lado." 9 No Qalândia, ao pé do muro, há essa pergunta impressa em cada rosto palestino, se essa é realmente uma esperança que se pode ter, se será possível não apenas transpor, mas superar esse novo elemento da opressão israelense: o muro da separação, da anexação.

\footnotetext{
8 DARWISH, Mahmoud. The Earth is Closing on Us. Translation: Abdullah al-Udhari, In Victims of a Map (London: al-Saqi Books, 1984), p. $\quad$ 13. Disponível em: < http://www.mehbooba.co.uk/poemsandpoetry/index.php?action=article\&cat_id=003002003002002\&id $=514>$. Acesso em: 01/09/2014.

9 SAID. Edward. A Pena e a Espada: diálogos com Edward Said por David Barsamian; tradução: Matheus Corrêa. São Paulo: Editora Unesp, 2013, p. 42. Mais a frente, Said aponta com uma esperança um pouco menor: “(...) é a sensação de saber que aparentemente estamos na última fronteira e no último céu, que não há nada depois disso, que estamos condenados à perdição - e, no entanto, fazemos a pergunta: "Para onde vamos daqui?" Queremos uma segunda opinião. Não basta ouvir do primeiro médico que estamos mortos. Queremos seguir adianta." (p. 46).
} 


\section{Referências bibliográficas}

BACKMANN, René. Um Muro na Palestina. Tradução de Clóvis Marques. Rio de Janeiro: 2012.

CARECCIA, Grazia; MONAGHAN, Lisa. The Annexation Wall and its

Associated Regime. Ramallah: Al-Haq, 2012.

DARWISH, Mahmoud. The Earth is Closing on Us. Translation: Abdullah al-Udhari, In Victims of a Map (London: al-Saqi Books, 1984), p. 13. Disponível em: < http://www.mehbooba.co.uk/poemsandpoetry/index.php?action=article\&cat_id=0 03002003002002\&id=514> . Acesso em: 01/09/2014.

ICJ (International Court of Justice. Advisory Opinion on Legal Consequences of the Construction of a Wall in the Occupied Palestinian Territory. Disponível em: <http://www.icj-cij.org/docket/index.php?p1=3\&p2=4\&case=131\&p3=4>. Acesso em 12/07/2014.

ICRC. IV Convenção de Genebra. Disponível em: < http://www.gddc.pt/direitoshumanos/textos-internacionais-dh/tidhuniversais/dih-conv-IV-12-08-1949.html>. Acesso em:

SAID, Edward. A Pena e a Espada: diálogos com Edward Said por David Barsamian; tradução: Matheus Corrêa. São Paulo: Editora Unesp, 2013.

ONU. Carta da Organização das Nações Unidas. Disponível em: < http://www.gddc.pt/direitos-humanos/textos-internacionaisdh/tidhuniversais/onu-carta.html>. Acesso em: 12/08/2014.

UNITED NATIONS. Fragmented Lives: Humanitarian Overview 2011. OCHA-oPt: 2012. 